\title{
Green synthetic route for perfumery compound (2-methoxyethyl) benzene using $\mathrm{Li} / \mathrm{MgO}$ catalyst
}

\author{
POOJA R TAMBE and GANAPATI D YADAV* (D) \\ Department of Chemical Engineering, Institute of Chemical Technology, Nathalal Parekh Marg, Matunga, \\ Mumbai, Maharashtra 400 019, India \\ E-mail: gdyadav@yahoo.com; gd.yadav@ictmumbai.edu.in
}

MS received 17 July 2017; revised 27 September 2017; accepted 28 September 2017; published online 16 November 2017

\begin{abstract}
Ethers are one of the most prominent compounds among perfumery chemicals. (2-Methoxyethyl) benzene commonly known as phenyl ethyl methyl ether (PEME) is widely used in flavour and fragrance industries. Conventionally, synthesis of PEME involves the use of hazardous and polluting chemicals, which in turn affects the purity of perfumery compound. Thus, developing a green route to synthesise PEME without any hazardous chemicals is desirable. In the current work, a new process is developed for the synthesis of PEME using solid base catalysts including $\mathrm{MgO}$ and $\mathrm{Li} / \mathrm{MgO}$ (with different loadings of lithium) and dimethyl carbonate (DMC) as a methylating agent as well as a solvent. Different kinetic parameters were studied to achieve the optimum yield of the desired product. At optimum reaction conditions i.e., $1000 \mathrm{rpm}$ of speed, $1.33 \times 10^{-2} \mathrm{~g} / \mathrm{cm}^{3}$ of catalyst loading, $1: 10.5$ mole ratio (2-Phenyl ethanol: DMC), $180{ }^{\circ} \mathrm{C}, 95 \%$ conversion of 2-phenyl ethanol with $98 \%$ selectivity of PEME was achieved. A detailed kinetic model was also developed and apparent activation energy for the reaction was calculated as $11.93 \mathrm{kcal} / \mathrm{mol}$.
\end{abstract}

Keywords. 2-Phenyl ethanol; (2-methoxyethyl)benzene; Li/MgO; perfumery compound; kinetics; solid base catalyst.

\section{Introduction}

Conventionally perfumery compounds are extracted from the natural sources but due to demanding trends in the market, the discovery of new synthetic pathways to prepare these compounds has received a lot of attention. Among a variety of organic compounds ethers, hemiacetals, etc., form an important group of compounds in perfumery and fragrance industry. Pandanus essential oil is a clear light yellow liquid highly soluble in water. The principal fragrance chemical constituent of the extract is phenyl ethyl methyl ether, which is responsible for the characteristic aroma of the flowers. Common pathways employed for the synthesis of phenyl ethyl methyl ether (PEME) are Williamson process using alkyl halides, ${ }^{1}$ dimethyl sulphide ${ }^{2}$ dimethyl sulfoxide ${ }^{3}$ and diazomethane ${ }^{4}$ as methylating agents. These processes require toxic solvents like THF, benzene, hexane, etc., and the amount of strong base required to catalyse this reaction is over the stoichiometry thus producing

\footnotetext{
*For correspondence
}

a large excess of dissolved inorganic salts and sideproducts. Though these processes are efficient the use of corrosive and toxic chemicals makes them environmentally hazardous. The industrial chemist, in his quest for aesthetic and creative solutions, must also take the cost and toxicity of the catalyst into account. Therefore, inventing a green catalytic route for the synthesis of PEME is desirable.

Dimethyl carbonate (DMC) has achieved a great attention as a methylating agent as it is an environmentally benign chemical ${ }^{5,6}$ and a better substitute to the corrosive and toxic methylating agents like dimethyl sulfoxide, ${ }^{7}$ methyl halides, etc. DMC favours the carboxymethylation with methanol as a co-product at a lower temperature, while at a higher temperature it favours the methylation reaction with methanol and carbon dioxide as co-products. ${ }^{7,8}$ The methylation of alcohol with DMC involves two steps, namely, transesterification followed by decarboxylation in the presence base catalyst. Selva et al., reported Y- and X-faujasites as base catalysts for the synthesis of methyl ethers from a variety of benzyl alcohols. ${ }^{9}$ They achieved $100 \%$ 
conversion of benzyl alcohol with $100 \%$ selectivity of desired methyl ether. Tundo et. al reported basic alumina and hydrotalcite as a catalyst for methylation of benzyl alcohol with DMC. With hydrotalcite, they reported $100 \%$ conversion of benzyl alcohol with $96 \%$ selectivity for benzyl methyl ether in $3 \mathrm{~h}$ while with basic alumina they achieved $93 \%$ conversion of benzyl alcohol and $77 \%$ selectivity of benzyl methyl ether. ${ }^{10}$

Yadav and Bokade reported a liquid phase synthesis of PEME using methanol as a methylating agent and heteropoly acid supported on K-10 (clay) as a catalyst. ${ }^{11}$ But there are no reports on the synthesis of PEME using DMC as a methylating agent. Thus, the aim of current work deals with the development of a new catalyst for synthesis of PEME using 2-phenyl ethanol (2-PE) and DMC.

Alkali promoted alkaline earth metal oxides are one of the well-known solid super-base catalysts and have been widely used as catalysts for a variety of reactions such as condensation, oxidative coupling, oxidative dehydrogenation, etc. ${ }^{12-17}$ These catalysts are prepared by different methods like co-precipitation, decomposition of carbonates, sol gel ${ }^{18}$ and incipient wetness technique. Conventionally synthesized $\mathrm{Li}$ promoted on magnesium oxides requires high-temperature treatment which results in sintering and lower surface area of the resultant catalyst. To employ the sol-gel method, magnesium alkoxides are used as precursors and is affected by the problems as these chemicals are quite expensive as well as moisture sensitive and unstable. Also, gelation process is quite time-consuming. Thus, catalyst synthesis route is needed with advantages of simplicity, ease of preparation, shorter time and cost-effective. ${ }^{17,19,20}$ Therefore, combustion method was employed to synthesize $\mathrm{Li} / \mathrm{MgO}$ catalyst with different Li loadings by a process developed in our lab. ${ }^{21}$ The structural properties of the catalyst were studied by different analytical techniques like BET surface area, TPD with $10 \% \mathrm{CO}_{2}$, SEM and XRD.

The main objective of the current work is to develop a solid base catalyst for synthesis of phenyl ethyl methyl ether selectively from 2-phenyl ethanol and to optimize the reaction parameters like the speed of agitation, catalyst loading, concentration and temperature, etc. and to develop a detailed mechanism and kinetic model for the process.

\section{Experimental}

\subsection{Chemicals}

All chemicals were purchased from reputed companies and used as received: Lithium nitrate, magnesium nitrate, glycine,

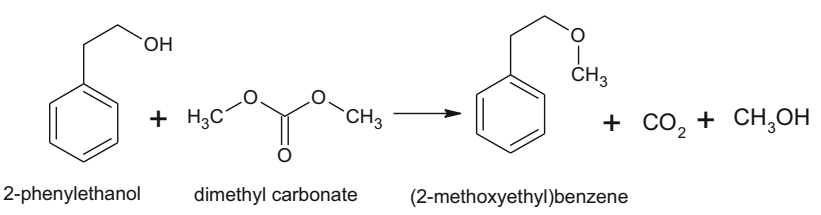

Scheme 1. o-Alkylation of 2-PE with dimethyl carbonate.

n-decane from M/s. S.D. Fine Chemicals Pvt. Ltd., Mumbai, India. Dimethyl carbonate was purchased from Alfa Aesar, Mumbai. Gift sample of 2-phenyl ethanol was received from U. K. Aromatics, Boisar, India.

\subsection{Preparation of $\mathrm{Li} / \mathrm{MgO}$}

All catalysts were synthesized by combustion method. Initially, $0.1 \% \mathrm{Li} / \mathrm{MgO}$ was synthesized as per the process reported by Yadav and Surve ${ }^{21}$ and described in SI section 1 . Using the same method pure $\mathrm{MgO}$ and $0.3 \% \mathrm{Li} / \mathrm{MgO}$ were also synthesized.

A typical reaction was carried out in an autoclave (Amar Equipments, Mumbai) of $100 \mathrm{~mL}$ capacity fitted with four blade stirrer, and a temperature controller. The reaction scheme is represented as Scheme 1. 2-Phenyl ethanol (0.0299 mol) was dissolved in DMC $(0.314 \mathrm{~mol})$ with a mole ratio of 2-PE to DMC as 1:10.05 and final volume of the reaction as 31 $\mathrm{mL}$. This was followed by addition of $0.2 \mathrm{~g}$ of catalyst to the reaction mixture. The reactor was heated to attain a temperature of $170^{\circ} \mathrm{C}$ and speed of agitation maintained at $1000 \mathrm{rpm}$. Samples were regularly withdrawn starting with zero minute. Samples were analysed by GC using BP-1 $(30 \mathrm{~cm} \times 0.03 \mu \mathrm{m})$ capillary column.

The product confirmation was done by Perkin Elmer GCMS (DB-5ht column).

\section{Results and Discussion}

\subsection{Catalyst characterization}

The catalysts were characterized by various techniques $^{22,23}$ and the details are given in the SI Section 2.

3.1a BET surface area analysis: The surface area analysis of $\mathrm{MgO}, \mathrm{Li} / \mathrm{MgO}$ with different loadings $(0.1 \%$ and $0.3 \%$ ) and reused catalysts were recorded by nitrogen adsorption-desorption technique by $\mathrm{BJH}$ and multipoint BET method (Figure 1). It was found that the BET surface area of the $\mathrm{MgO}$ was higher than that of alkali-promoted $\mathrm{MgO}$ (Table 1). As the loading of alkali on $\mathrm{MgO}$ is increased there was a decrease in the BET surface area which could be due to deposition of excess $\mathrm{Li}_{2} \mathrm{O}$ in a few junctions of pore network thus blocking the pores. The catalyst had mesoporous nature as it showed Type IV adsorption desorption isotherm with 


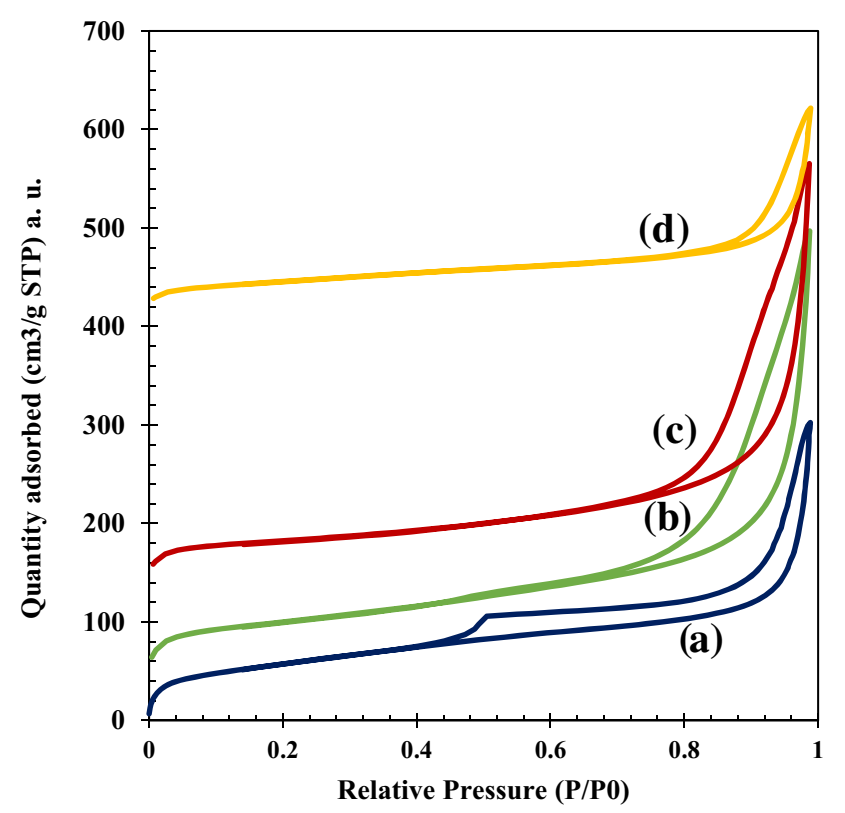

Figure 1. BET surface area analysis (a) $\mathrm{MgO}$, (b) $0.1 \%$ $\mathrm{Li} / \mathrm{MgO}$, (c) reused $0.1 \% \mathrm{Li} / \mathrm{MgO}$ and (d) $0.3 \% \mathrm{Li} / \mathrm{MgO}$.

Table 1. Textural properties of catalysts.

\begin{tabular}{lccc}
\hline Catalyst & $\begin{array}{c}\text { BET surface } \\
\text { area }\left(\mathrm{m}^{2} / \mathrm{g}\right)\end{array}$ & $\begin{array}{l}\text { Pore } \\
\text { size }(\mathrm{nm})\end{array}$ & $\begin{array}{l}\text { Pore volume } \\
\left(\mathrm{cm}^{3} / \mathrm{g}\right)\end{array}$ \\
\hline $\mathrm{MgO}$ & 204.20 & 13.25 & 0.62 \\
$0.1 \% \mathrm{Li} / \mathrm{MgO}$ & 185.24 & 12.96 & 0.58 \\
$0.3 \% \mathrm{Li} / \mathrm{MgO}$ & 117.21 & 11.79 & 0.49 \\
$\begin{array}{l}\text { Reused } 0.1 \% \\
\mathrm{Li} / \mathrm{MgO}\end{array}$ & 154.50 & 12.52 & 0.51 \\
\hline
\end{tabular}

H3 type hysteresis. There was no substantial difference in the BET surface area of the reused catalyst compared well to the virgin catalyst. This validates that the catalyst retains the mesoporosity even after reuse.

$3.1 \mathrm{~b} \mathrm{CO}_{2}$ - temperature programmed desorption (TPD): The $\mathrm{CO}_{2}$ TPD analysis is given for $\mathrm{MgO}$, $\mathrm{Li} / \mathrm{MgO}$ with different loadings $(0.1 \%$ and $0.3 \%)$ and reused catalyst $0.1 \% \mathrm{Li} / \mathrm{MgO}$ (Figure 2 ). The basicity trend is: $\mathrm{MgO}$ (least) $<0.3 \% \mathrm{Li} / \mathrm{MgO}<0.1 \% \mathrm{Li} / \mathrm{MgO}$ (highest) based on the strength (concentration of weak, medium and strong basic sites in $\mathrm{mmol} / \mathrm{g}$ ) and total basicity of catalyst (Table 2). This confirms that there is an increase in total basicity of $\mathrm{MgO}$ with the incorporation of $\mathrm{Li}$ in its lattice structure. With loading of $\mathrm{Li}$ of $0.3 \%$ the pore size and pore volume of $\mathrm{MgO}$ is decreased resulting in a decrease in total surface basicity due to $\mathrm{Li}_{2} \mathrm{O}$ trapped inside the pores of $\mathrm{MgO}$ as was mentioned above. Depending upon temperature, there are three regions to signify the strength of basicity, namely,

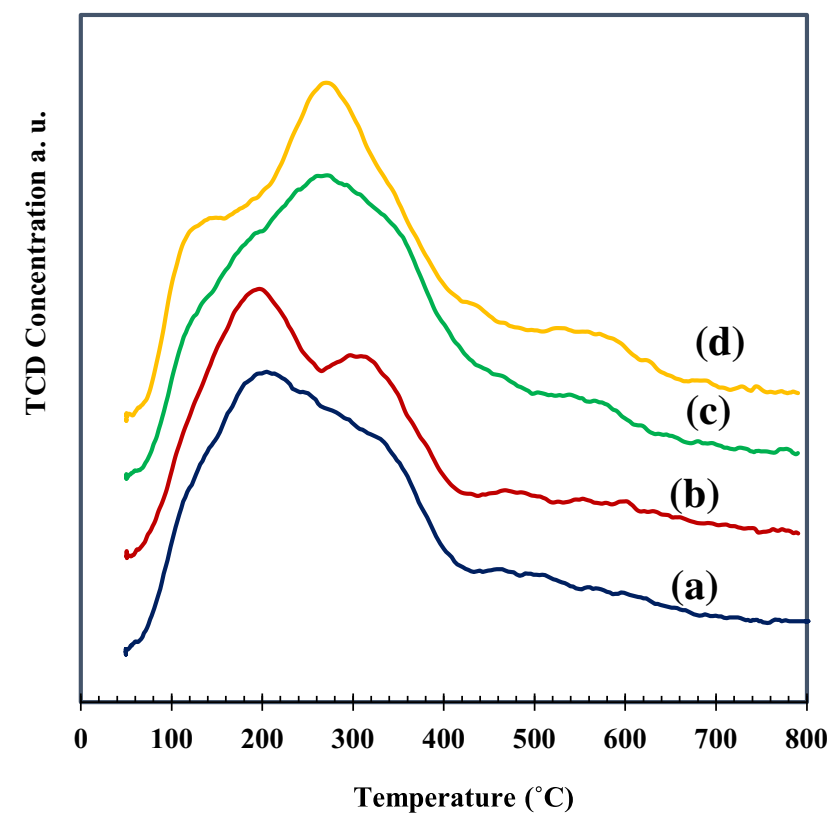

Figure 2. TPD Analysis with $10 \% \mathrm{CO}_{2}$ (a) $\mathrm{MgO}$, (b) $0.1 \%$ $\mathrm{Li} / \mathrm{MgO}$, (c) $0.3 \% \mathrm{Li} / \mathrm{MgO}$ and (d) reused $0.1 \% \mathrm{Li} / \mathrm{MgO}$.

Table 2. The concentration of different basic sites

\begin{tabular}{lcccc}
\hline Catalyst & Weak & $\begin{array}{l}\text { Basicity (mmol/g) } \\
\text { Medium }\end{array}$ & Strong & Total \\
\hline $\mathrm{MgO}$ & 0.13 & 0.40 & 0.08 & 0.61 \\
$0.1 \% \mathrm{Li} / \mathrm{MgO}$ & 0.12 & 0.53 & 0.11 & 0.76 \\
$0.3 \% \mathrm{Li} / \mathrm{MgO}$ & 0.12 & 0.46 & 0.07 & 0.65 \\
Reused 0.1\% & 0.11 & 0.51 & 0.09 & 0.71 \\
$\mathrm{Li} / \mathrm{MgO}$ & & & & \\
\hline
\end{tabular}

$100-150^{\circ} \mathrm{C}$ as weak basic, $150-450{ }^{\circ} \mathrm{C}$ as moderate basic and finally $450-750^{\circ} \mathrm{C}$ as strong basic sites. $\mathrm{MgO}, \mathrm{Li} / \mathrm{MgO}$ with different loadings $(0.1 \%$ and $0.3 \%)$ and reused catalyst $0.1 \% \mathrm{Li} / \mathrm{MgO}$ showed peaks in the region of $100-150^{\circ} \mathrm{C}, 150-450{ }^{\circ} \mathrm{C}$ and $450-750{ }^{\circ} \mathrm{C}$ signifying weak, moderate and a few strong basic sites are present.

\subsection{Scanning electron microscopy (SEM)}

SEM images for fresh and reused catalyst were obtained (Figure 3). Irregular morphology was observed for all synthesized catalysts which is a characteristic of the combustion synthesized catalyst due to the evolution of gases $\left(\mathrm{CO}_{2}\right.$ and $\left.\mathrm{N}_{2}\right)$ during the combustion process. Despite irregular morphology, the catalyst showed uniform particle size in the range of $20-100 \mathrm{~nm}$. No significant change in the morphology and particle size for reused catalyst was observed (Figure $3 b$ ). This confirms the retention of catalytic activity of catalyst even after the reuse. 

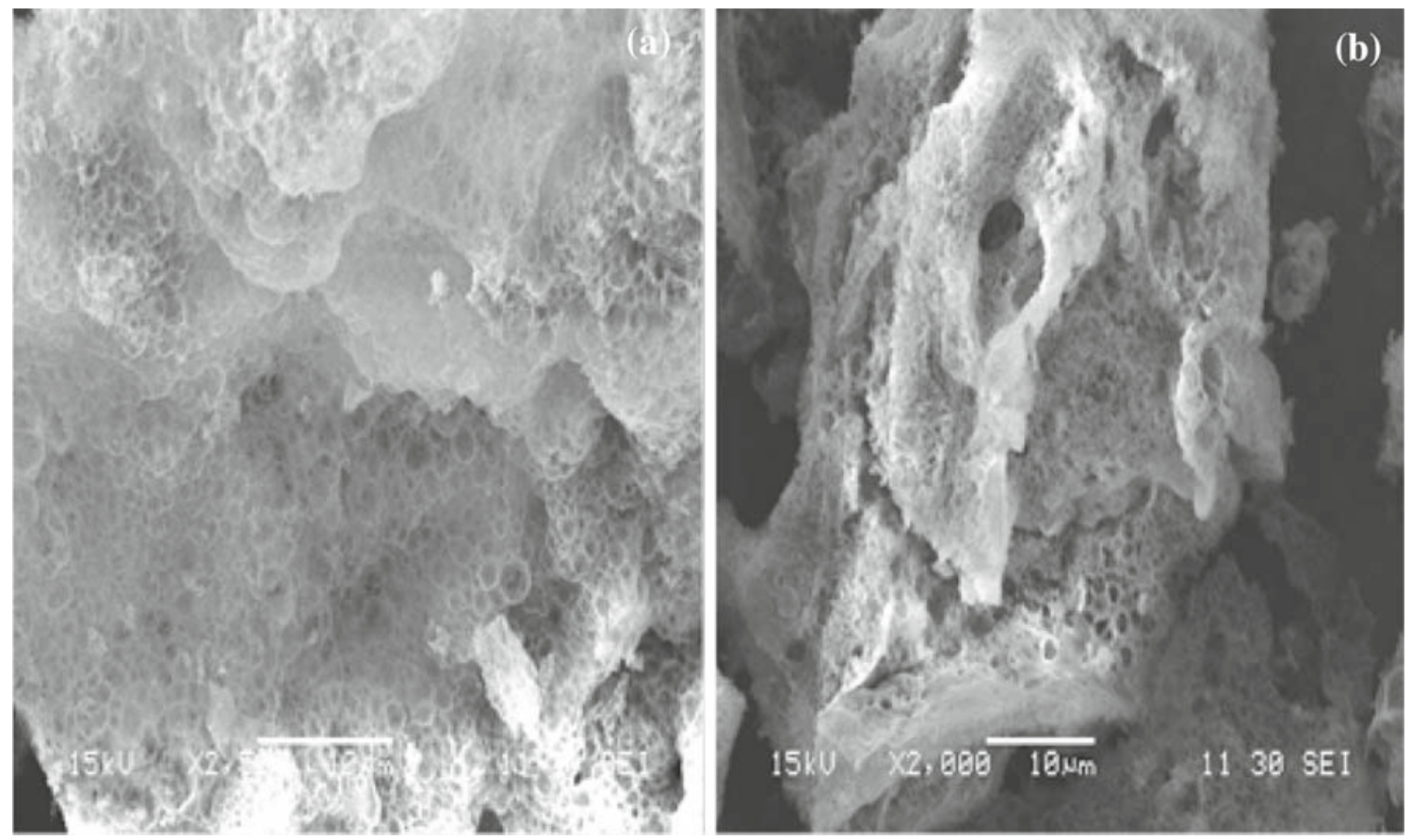

Figure 3. SEM analysis (a) $0.1 \% \mathrm{Li} / \mathrm{MgO}$, (b) reused $0.1 \% \mathrm{Li} / \mathrm{MgO}$.

3.2a X-ray diffraction (XRD): XRD patterns were recorded for pure $\mathrm{MgO}, \mathrm{Li} / \mathrm{MgO}$ with different loadings $(0.1 \%$ and $0.3 \%)$ to understand the effect of Li loading on the crystal structure of $\mathrm{MgO}$ (Figure 4). The diffraction peaks are observed for all samples at $2 \theta$ values of $37.1,42.8$ and $62.4^{\circ}$ which are characteristics peaks representing a single phase of $\mathrm{MgO}$ periclase. In the case of $0.1 \%$ and $0.3 \% \mathrm{Li} / \mathrm{MgO}$ we observed a peak at $2 \theta$ of $33^{\circ}$ which confirmed the presence of $\mathrm{Li}$ in the form of $\mathrm{Li}_{2} \mathrm{O}$ (JCPD 12-0254). Pure $\mathrm{Li}_{2} \mathrm{CO}_{3}$ shows peaks at $2 \theta$ of $21,23.8,29.7,30.5,31.6,34,36,37,39.6$ and $48.5^{\circ}$. These peaks were absent in $\mathrm{MgO}$ and $\mathrm{Li} / \mathrm{MgO}$ with different loadings $(0.1 \%$ and $0.3 \%)$ confirms that the $\mathrm{Li}$ is present in the $\mathrm{Li}_{2} \mathrm{O}$ form and not in the carbonate form. The shift in the peak at $2 \theta$ of $37.1^{\circ}$ for $0.3 \%$ $\mathrm{Li} / \mathrm{MgO}$ may be due to deposition of $\mathrm{Li}$ as $\mathrm{Li}_{2} \mathrm{CO}_{3}$ as the characteristic peaks for $\mathrm{Li}_{2} \mathrm{CO}_{3}$ are $2 \theta=21,23.8$, $29.7,30.5,31.6,34,36,37,39.6$ and $48.5^{\circ}$ from which it is inferred that $\mathrm{Li}$ might be deposited as $\mathrm{Li}_{2} \mathrm{CO}_{3}$ after $0.1 \%$ loading of $\mathrm{Li}$.

\subsection{Optimization of reaction parameters}

3.3a Catalyst screening: A variety of base catalysts were screened for the synthesis of PEME from 2-PE and DMC like pure $\mathrm{MgO}, 0.1 \% \mathrm{Li} / \mathrm{MgO}, 0.3 \% \mathrm{Li} / \mathrm{MgO}$ and $0.1 \% \mathrm{~K} / \mathrm{MgO}$ (Figure 5). Among all the screened catalysts $0.1 \% \mathrm{Li} / \mathrm{MgO}$ was found to be a better catalyst in terms of conversion of 2-PE and selectivity of PEME.

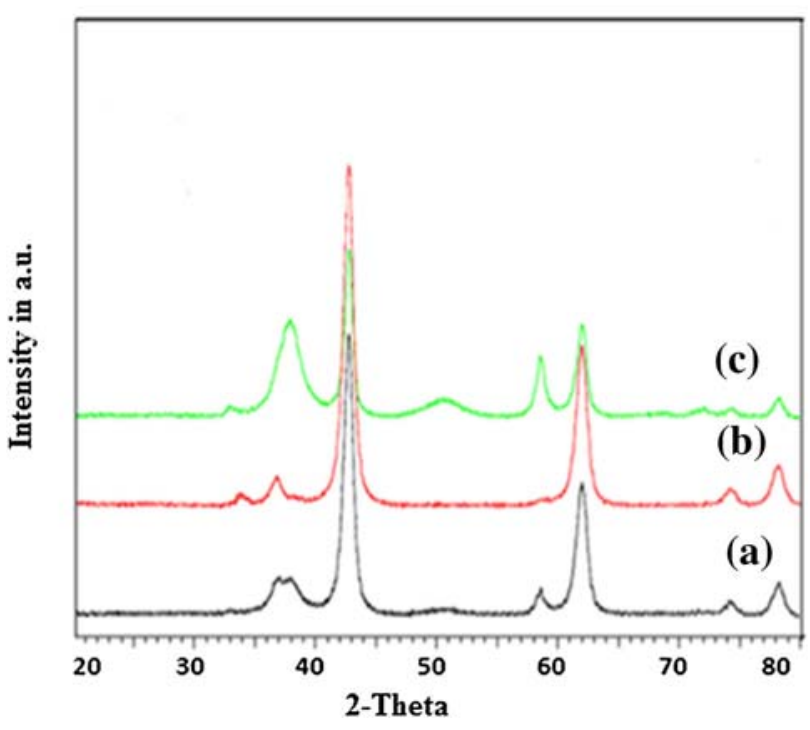

Figure 4. XRD Analysis (a) $\mathrm{MgO}$, (b) $0.1 \% \mathrm{Li} / \mathrm{MgO}$ and (c) $0.3 \% \mathrm{Li} / \mathrm{MgO}$.

The surface basicity of $\mathrm{MgO}$ is increased with the incorporation of $\mathrm{Li}$ on $\mathrm{MgO}$. Thus, using unsupported $\mathrm{MgO}$ as a catalyst we got only $65 \%$ conversion. Even though the basicity increases in the order of $\mathrm{MgO}$ (least) < $0.3 \% \mathrm{Li} / \mathrm{MgO}<0.1 \% \mathrm{Li} / \mathrm{MgO}<0.1 \% \mathrm{~K} / \mathrm{MgO}$ (highest), the acidic sites required for successive methylation are present only in $0.1 \% \mathrm{Li} / \mathrm{MgO} .^{21}$

Thus, better conversion of 2-PE, as well as better selectivity of PEME, was achieved with $0.1 \% \mathrm{Li} / \mathrm{MgO}$ 


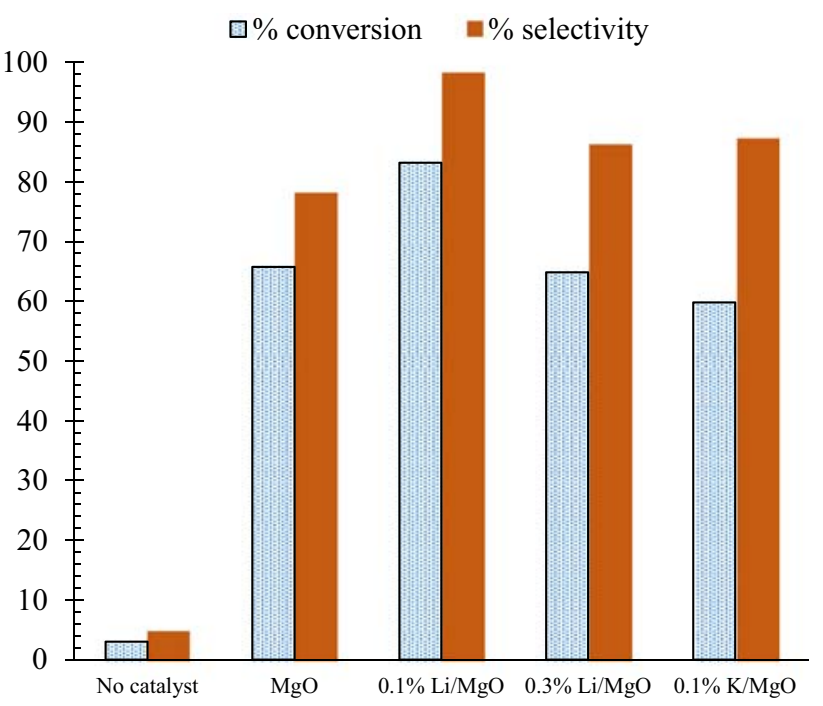

Figure 5. Efficacy of different catalyst on conversion of 2-PE and selectivity of PEME, Catalyst: $0.1 \% \mathrm{Li} / \mathrm{MgO}$, catalyst concentration: $1.13 \times 10^{-2} \mathrm{~g} / \mathrm{cm}^{3}$, temperature $170^{\circ} \mathrm{C}$, 2-PE: $\mathrm{DMC}=1: 10.5$, speed of agitation: $800 \mathrm{rpm}$, time 3 h.

as a catalyst. And hence it was used as the best catalyst in the further experiments.

3.3b Speed of agitation: The effect of external mass transfer resistance was studied by varying the speed of agitation in the range of 800-12000 rpm (Figure 6). It was observed that rate of reaction increased with speed agitation from 800 to $1000 \mathrm{rpm}$ indicating the presence of external mass transfer resistance of reactants to the surface of the catalyst. But beyond $1000 \mathrm{rpm}$ the rate of reaction did not change significantly which implied that the reaction is free from mass transfer resistance and thus further experiments were carried out at 1000 $\mathrm{rpm}$. The details for the absence of external mass transfer resistance are provided in earlier work ${ }^{24,25}$ and explained in SI section 5.

3.3c Catalyst loading: Once the reaction is free from external mass transfer resistance, the reaction rate is dependent on catalyst loading. Thus, to study the effect of catalyst loading on reaction rate the catalyst concentration was varied from $6.6 \times 10^{-3}$ to $2 \times 10^{-2} \mathrm{~g} / \mathrm{cm}^{3}$ (Figure 7). It was observed that there was a liner increase in the reaction rate with a catalyst loading. But beyond, $1.3 \times 10^{-2} \mathrm{~g} / \mathrm{cm}^{3}$ of catalyst loading the total active sites available were more than those required for adsorption and therefore no change was observed in reaction rate. For further studies, the catalyst concentration was optimised at to $1.3 \times 10^{-2} \mathrm{~g} / \mathrm{cm}^{3}$. The details to prove the absence of intra-particle resistance are explained in some of earlier work ${ }^{25,26}$ and given in SI section 6.

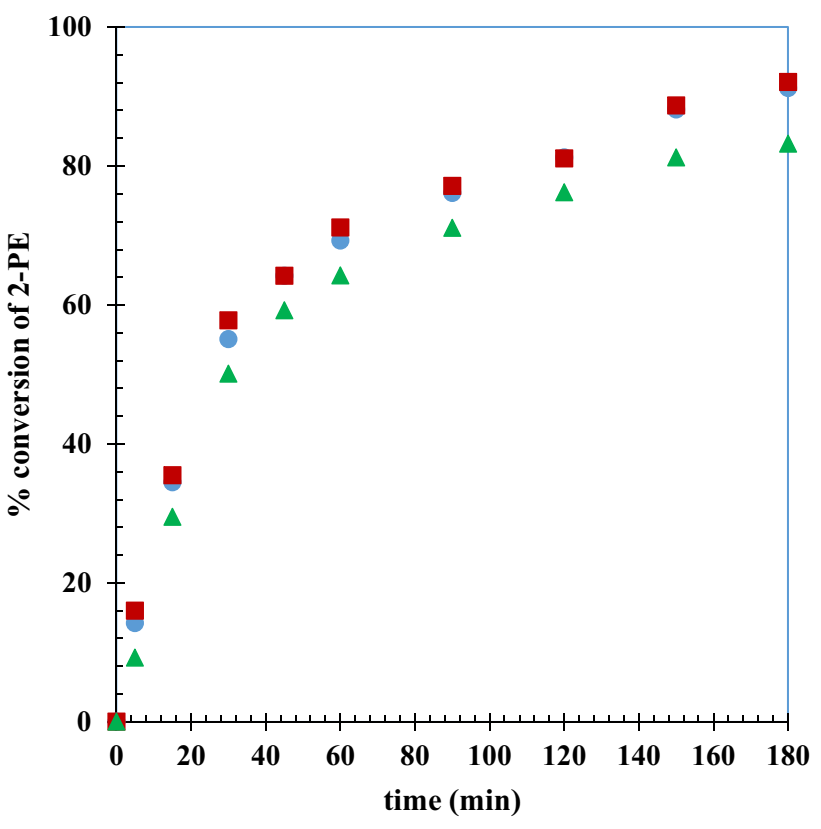

Figure 6. Effect of speed of agitation on conversion of 2-PE, Catalyst: $0.1 \% \mathrm{Li} / \mathrm{MgO}$, catalyst concentration: $1.13 \times 10^{-2} \mathrm{~g} / \mathrm{cm}^{3}$, temperature $170^{\circ} \mathrm{C}, 2-\mathrm{PE}: \mathrm{DMC}=$ 1:10.5, (匹) $1200 \mathrm{rpm}$ (О) $1000 \mathrm{rpm}$ (А) $800 \mathrm{rpm}$.

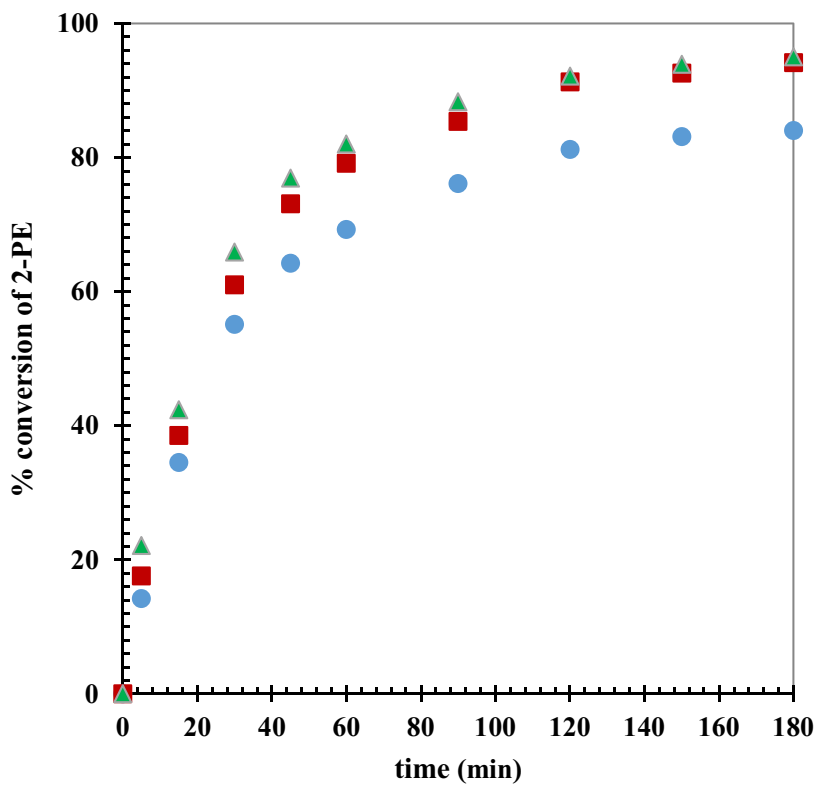

Figure 7. Effect of catalyst loading $\left(\mathrm{g} / \mathrm{cm}^{3}\right)$ on conversion of 2-PE, Catalyst: $0.1 \% \mathrm{Li} / \mathrm{MgO}$, temperature $170{ }^{\circ} \mathrm{C}$, 2-PE: $\mathrm{DMC}=1: 10.5$, (О) $6.6 \times 10^{-3}$ (ㅁ) $1.13 \times 10^{-2}(\mathbf{\Delta})$ $2.0 \times 10^{-2} \mathrm{~g} / \mathrm{cm}^{3}$.

3.3d Mole ratio of 2-PE to DMC: The effect of mole ratio of 2-PE to DMC on the reaction rate was studied at $1: 4.9,1: 10.5$ and $1: 20.06$ (Figure 8 ) by keeping all other reaction conditions constant. A linear increase in initial rate of reaction of 2-PE was observed with increase in mole ratio of 2-PE: DMC. For further experiments 1 : 


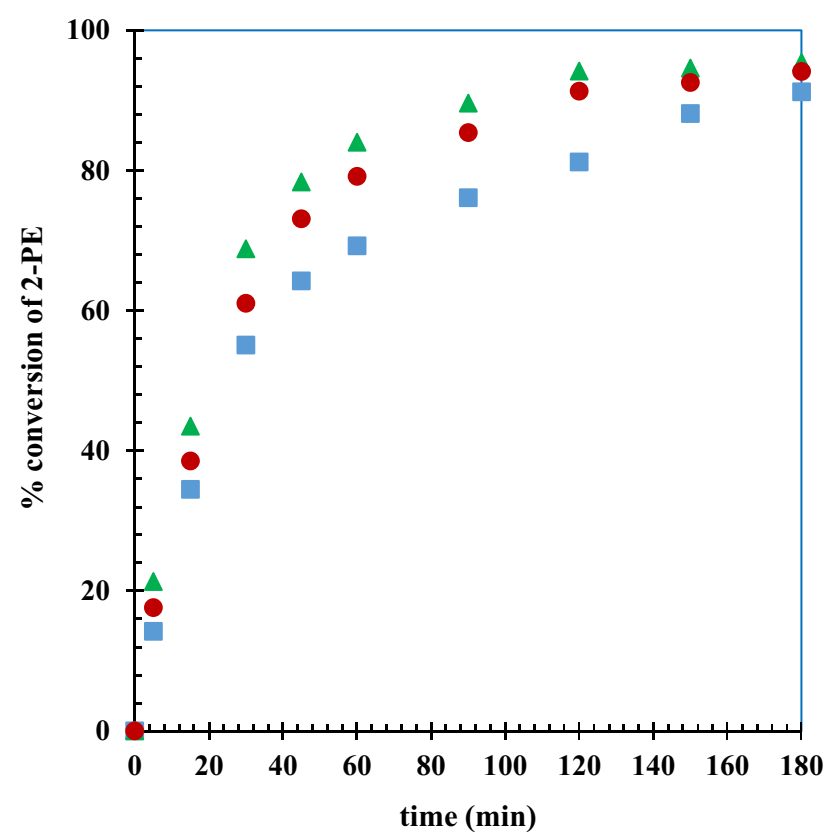

Figure 8. Effect of mole ratio of 2-PE: DMC, Catalyst: $0.1 \% \mathrm{Li} / \mathrm{MgO}$, catalyst concentration: $1.13 \times 10^{-2} \mathrm{~g} / \mathrm{cm}^{3}$, temperature $170^{\circ} \mathrm{C}$, speed of agitation $1000 \mathrm{rpm}$, (口) 1:4.9 (O) $1: 10.5$ (ㅅ) 1:20.06.

10.5 mole ratio of 2-PE: DMC was taken as optimum mole ratio as good conversion and selectivity for PEME were achieved at this mole ratio.

3.3e Temperature: Under the same reaction conditions, the reaction temperature was varied from $160-$ $190{ }^{\circ} \mathrm{C}$ to study its effect on reaction rate (Figure 9). The reaction rate increased substantially with temperature which suggested that the reaction was kinetically controlled.

3.3f Reusability and stability of Catalyst: After the completion of the reaction the catalyst was filtered from the reaction. It was refluxed with methanol for $1 \mathrm{~h}$ to remove any adsorbed materials. The catalyst was filtered again and dried at $120^{\circ} \mathrm{C}$ and calcined at $500^{\circ} \mathrm{C}$ for $4 \mathrm{~h}$. This catalyst was used in the further reusability experiments. The loss in the weight of the reused catalyst was recovered by adding fresh catalyst (approx. $5 \%$ of total weight) and experiments were done under the same reaction conditions. There was no significant decrease in the conversion of 2-PE and selectivity of product for three catalytic cycles (Figure 10). This confirmed that the catalyst retained its activity over three cycles.

Leaching test of catalyst in the liquid phase was done by stopping the reaction after $30 \mathrm{~min}$ and immediately quenching the reaction mixture to arrest the reaction

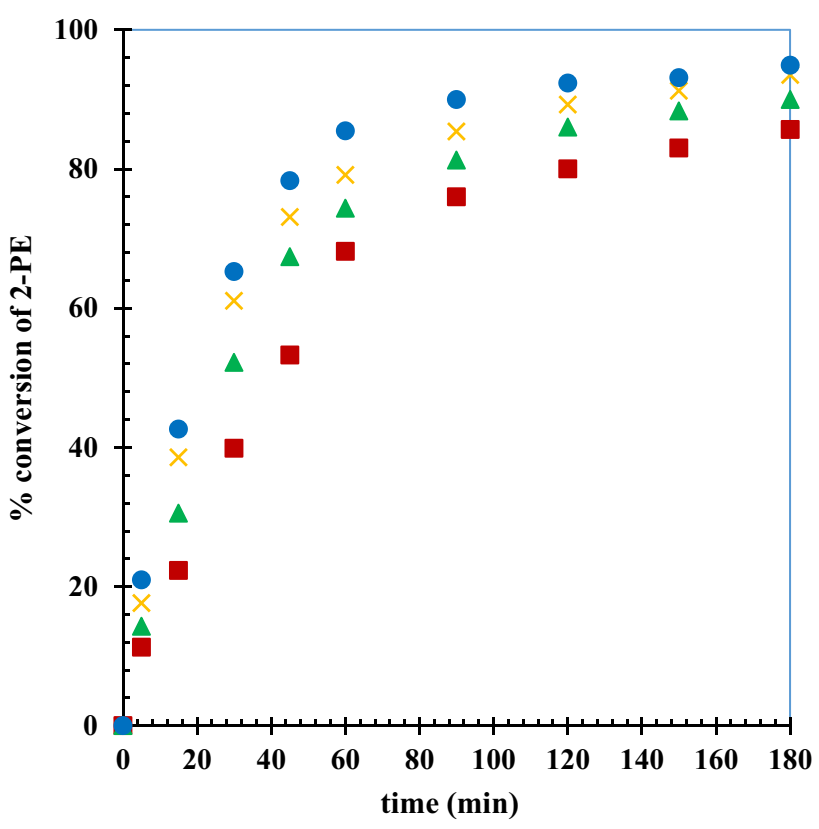

Figure 9. Effect of Temperature on conversion of OPDA, Catalyst: $0.1 \% \mathrm{Li} / \mathrm{MgO}$ catalyst concentration: $0.0133 \mathrm{~g} / \mathrm{cm}^{3}$, speed of agitation $1000 \mathrm{rpm},(\square) 150^{\circ} \mathrm{C}$ (A) $160^{\circ} \mathrm{C}$ (X) $170^{\circ} \mathrm{C}$; (O) $180^{\circ} \mathrm{C}$.

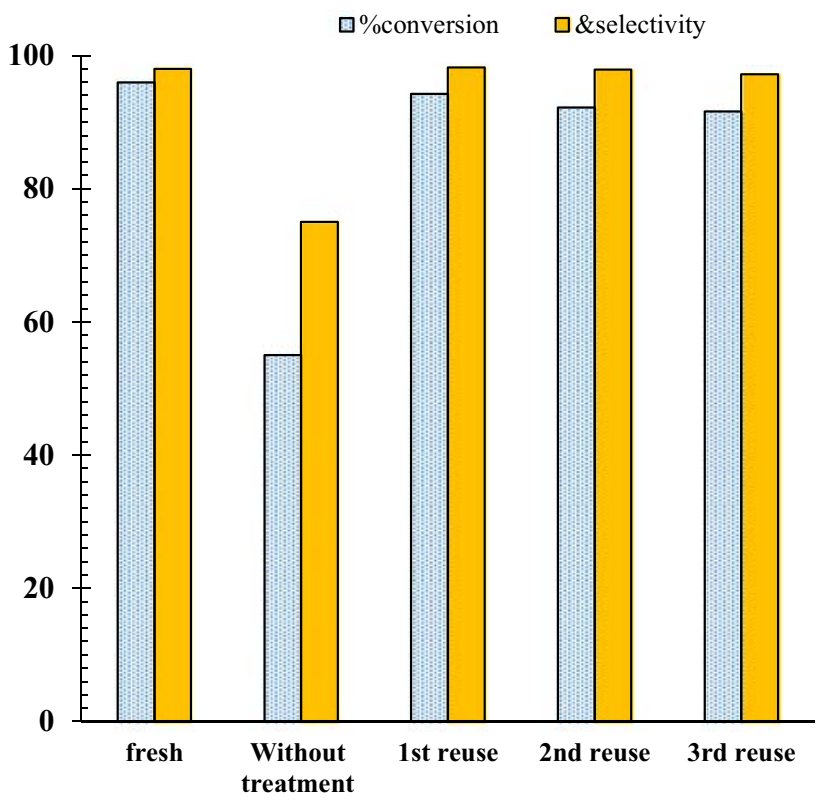

Figure 10. Reusability of catalyst.

progress followed by centrifuging the reaction mixture. The separated clear supernatant reaction mixture was then charged into the reactor and continued reaction under the same condition without any traces of catalyst. There was practically no conversion during next two hours which suggests that catalyst is stable and there is no leaching of alkali metal into the reaction mass. 


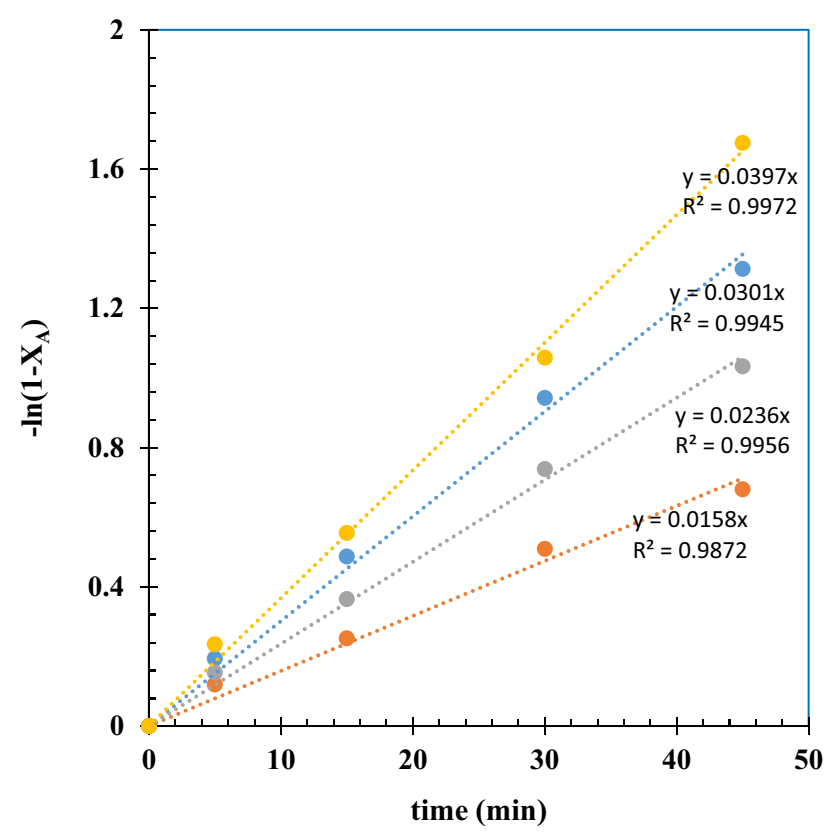

Figure 11. Plot of $-\ln \left(1-X_{A}\right)$ vs time for different temperatures.

\subsection{Kinetic model and mechanism}

A plausible mechanism for the reaction is given in Scheme 2. The kinetic model for this reaction can be explained by LHHW model ${ }^{24,26}$ where 2-PE (A) is adsorbed on the basic sites of the catalyst while DMC (B) was adsorbed on the acidic sites to form an intermediate. This intermediate rearranges to give PEME with carbon dioxide and methanol as co-products. During analysis, it was observed that all the reactants were weakly adsorbed on the catalytic sites. Thus, the power law was applied to get the rate of reaction as,

$$
\begin{aligned}
& -\frac{d C_{A}}{d t}=k_{1} K_{A} K_{B} w C_{A} C_{B} \\
& \frac{-d C_{A}}{d_{t}}=k_{2} C_{A} C_{B}
\end{aligned}
$$

Where, $k_{2}=k_{1} K_{A} K_{B} w$

Let $C_{B_{0}} / C_{A_{0}}=M$ be the molar ratio of 2-PE to DMC at time $\mathrm{t}=0$. Equation (2) can be written in terms of fractional conversion as:

$$
\frac{d X_{A}}{d_{t}}=k_{2} C_{A_{0}}\left(1-X_{A}\right)\left(M-X_{A}\right)
$$

Above equation on integration gives:

$\ln \frac{\left(M-X_{A}\right)}{M\left(1-X_{A}\right)}=k_{2} C_{A_{0}}(M-1) t$

When $\mathrm{M}>>1$, equation (4) can be written for pseudofirst order as:

$$
-\ln \left(1-X_{A}\right)=k t
$$

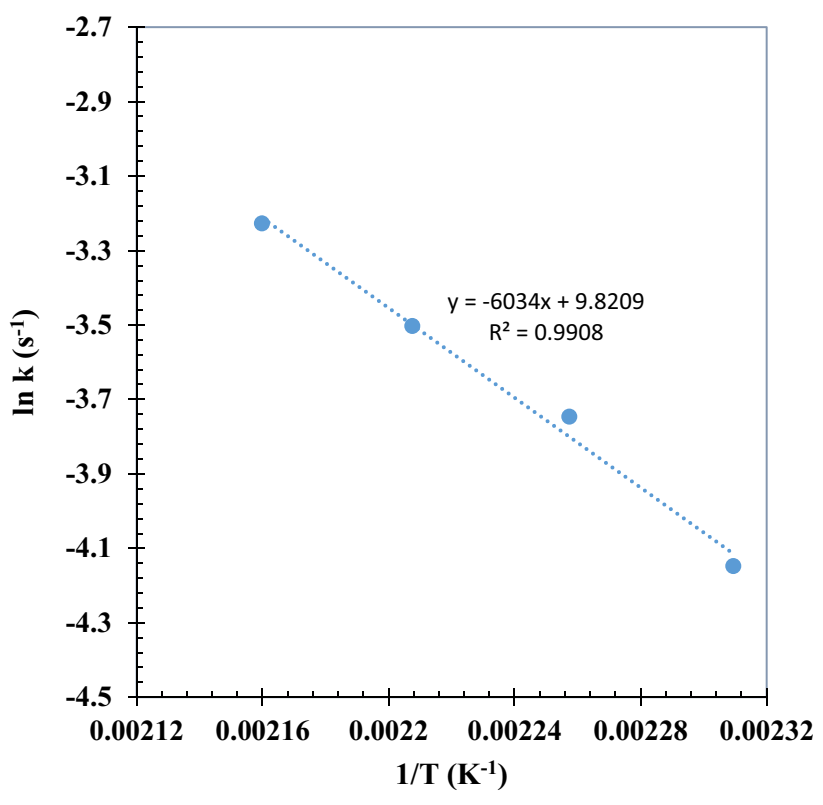

Figure 12. Arrhenius plot.

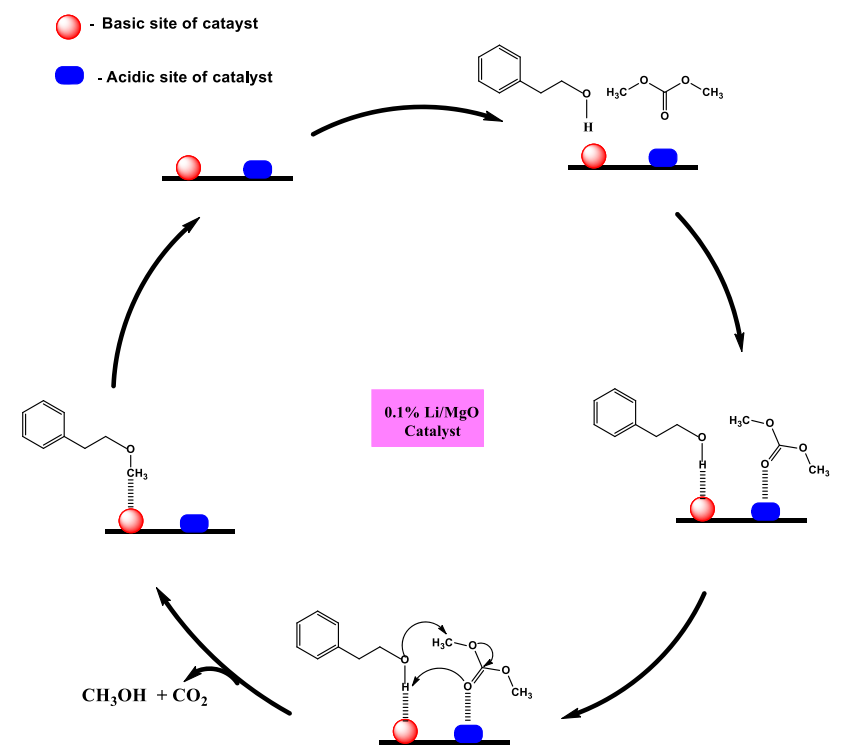

Scheme 2. Mechanism of $o$-methylation of 2-PE.

Thus, plots of $-\ln \left(1-\mathrm{X}_{\mathrm{A}}\right)$ vs time (Figure 11) were drawn for different temperatures to prove a linear relation, where $\mathrm{X}_{\mathrm{A}}$ is the fractional conversion of 2-PE. The reaction followed the pseudo first order kinetics. The model was validated by plotting it for different temperature and the slopes of these lines are used to plot the Arrhenius plot (Figure 12). The apparent activation energy was calculated as $11.93 \mathrm{kcal} / \mathrm{mol}$, signifying that the reaction is kinetically controlled. 


\subsection{Mechanism}

$0.1 \% \mathrm{Li} / \mathrm{MgO}$ provides both acidic and basic sites. There is adsorption of 2-PE on basic sites provided by catalyst through hydrogen atom while dimethyl carbonate is adsorbed on acidic sites of the catalyst. The carboxymethylation takes place at a lower temperature $\left(\mathrm{T} \leq 120^{\circ} \mathrm{C}\right.$ ) while methylation is favoured at a higher temperature $\left(\mathrm{T}>>120^{\circ} \mathrm{C}\right) .{ }^{8}$ Thus, the reaction proceeds with an attack of a lone pair of electrons on methyl group, to give an unstable intermediate. This intermediate rearranges to PEME as a product with methanol and carbon dioxide as co-products. PEME is desorbed from catalyst surface into the solution and leaves the catalytic sites vacant for the next adsorption.

\section{Conclusion}

The green catalytic route to synthesise phenyl ethyl methyl ether from 2-PE and DMC was invented using $0.1 \% \mathrm{Li} / \mathrm{MgO}$ as a catalyst which holds wide applications as a perfumery compound. The prepared catalyst as well as reused catalyst, were well-characterised by different analytical techniques to understand its surface properties like surface area, total basicity, pore size, pore volume, etc. A detailed kinetic model was developed for etherification of 2-PE by studying different reaction parameters. At optimum conditions i.e., $1000 \mathrm{rpm}, 1.33 \times 10^{-2} \mathrm{~g} / \mathrm{cm}^{3}$ catalyst loading, 1:10.5 mole ration (2-PE: DMC), $180{ }^{\circ} \mathrm{C}$, 95\% conversion of 2-phenyl ethanol and 98\% selectivity of PEME was achieved. The reaction follows the LHHW model with weak adsorption of all species leading to second order kinetics and apparent activation energy for the reaction was calculated as 11.93 $\mathrm{kcal} / \mathrm{mol}$.

\section{Supplementary Information (SI)}

The detailed method for synthesis of $\mathrm{Li} / \mathrm{MgO}$ with different loadings and $\mathrm{MgO}$ is given in the supplementary. Catalysts were characterized by various techniques and details are provided in the supplementary information. The details of the absence of mass transfer resistance and intra-particle resistance are also given in the supplementary.

\section{Acknowledgements}

This work was done under the collaborative project "Sustainable Catalytic Syntheses of Chemicals using Carbon Dioxide as Feedstock (GreenCatCO2)" supported by the Department of Science and Technology, Government of India (DST-GOI) and the Academy of Finland. GDY acknowledges support from R. T. Mody Distinguished Professor Endowment and
J.C. Bose National Fellowship from DST-GOI. Pooja Tambe acknowledges the Department of Science and Technology for awarding the Junior Research Fellowship under Indo- Finnish Project

\section{References}

1. Stoochnoff B A and Benoiton N L 1973 The methylation of some phenols and alcohols with sodium hydride/methyl iodide in tetrahydrofuran at room temperature Tetrahedron Lett. 1421

2. Blagg J, Davies S G, Holman N J, Laughton C A and Mobbs B E 1986 Elaboration of $\alpha$-substituted benzyl alkyl ethers and sulphides by suppression of the Wittig and related rearrangements via complexation to tricarbonylchromium J. Chem. Soc. Perkin Trans. 11581

3. Ogawa H, Ichimura Y, Chihara T, Teratani S and Taya K 1986 Methylation of alcohols, phenols, and carboxylic acids, and selective monomethylation of diols and dicarboxylic acids with dimethyl sulfate by use of alumina Bull. Chem. Soc. Jpn. 592481

4. Ogawa H, Hagiwara T, Chihara T, Teratani S and Taya K 1987 Methylation of alcohols and phenols adsorbed on silica gel with diazomethane Bull. Chem. Soc. Jpn. 60 627

5. Ono Y 1997 Catalysis in the production and reactions of dimethyl carbonate, an environmentally benign building block Appl. Catal. A Gen. 155133

6. Shaikh A A G and Sivaram S 1996 Organic carbonates Chem. Rev. 96951

7. Davis W A 1900 IV.-Etherification of derivatives of $\beta$-naphthol J. Chem. Soc. Trans. 7733

8. Yadav G D and Krishnan M S 1998 Etherification of $\beta$ naphthol with alkanols using modified clays and sulfated zirconia Ind. Eng. Chem. Res. 373358

9. Selva M, Militello E and Fabris M 2008 The methylation of benzyl-type alcohols with dimethyl carbonate in the presence of Y-and X-faujasites: selective synthesis of methyl ethers Green Chem. 1073

10. Tundo P, Memoli S, Hérault D and Hill K 2004 Synthesis of methylethers by reaction of alcohols with dimethylcarbonate Green Chem. 6609

11. Yadav GD and Bokade V V 1996 Novelties of heteropoly acid supported on clay: etherification of phenethyl alcohol with alkanols Appl. Catal. A Gen. 147299

12. Di Cosimo J I, Diez V K and Apesteguía C R 1996 Base catalysis for the synthesis of $\alpha, \beta$-unsaturated ketones from the vapor-phase aldol condensation of acetone Appl. Catal. A Gen. 137149

13. Cortes-Concepcion J A, Patcas F and Amiridis M D 2010 Effect of $\mathrm{Li}$ on the catalytic activity of $\mathrm{MgO}$ for the synthesis of flavanone Appl. Catal. A Gen. 3861

14. Leveles L, Seshan K, Lercher J A and Lefferts L 2003 Oxidative conversion of propane over lithium-promoted magnesia catalyst: I. Kinetics and mechanism J. Catal. 218296

15. Trionfetti C, Crapanzano S, Babich I V, Seshan K and Lefferts L 2009 Lithium ions incorporation in $\mathrm{MgO}$ for oxidative dehydrogenation/cracking of propane: Active 
site characterization and mechanism of regeneration Catal. Today 14519

16. Díez V K, Apesteguía C R and Di Cosimo J I 2006 Aldol condensation of citral with acetone on $\mathrm{MgO}$ and alkalipromoted $\mathrm{MgO}$ catalysts J. Catal. 240235

17. Vijayaraj M and Gopinath C S 2006 Selective production of methoxyphenols from dihydroxybenzenes on alkali metal ion-loaded MgO J. Catal. 243376

18. Boldú J L, Munoz E, Bokhimi X, Novaro O, López T and Gómez R 1999 Spectroscopic Studies of Sol- Gel Li/MgO Catalysts Langmuir 1532

19. Nagappa B and Chandrappa G T 2007 Mesoporous nanocrystalline magnesium oxide for environmental remediation Microporous Mesoporous Mater. 106212

20. Reddy M B M, Ashoka S, Chandrappa G T and Pasha M A 2010 Nano-MgO: an efficient catalyst for the synthesis of formamides from amines and formic acid under MWI Catal. Lett. 13882

21. Yadav G D and Surve P S 2013 Solventless green synthesis of 4-O-aryloxy carbonates from aryl/alkyloxy propanediols and dimethyl carbonate over nanocrystalline alkali promoted alkaline earth metal oxides Catal. Sci. Technol. 32668
22. Gawade A B, Tiwari M S and Yadav G D 2016 Biobased Green Process: Selective Hydrogenation of 5Hydroxymethylfurfural to 2, 5-Dimethyl Furan under Mild Conditions Using Pd-Cs2. 5H0. 5PW12O40/K-10 Clay ACS Sustain. Chem. Eng. 44113

23. Tiwari M S, Gawade A B and Yadav G D 2017 Magnetically separable sulfated zirconia as highly active acidic catalysts for selective synthesis of ethyl levulinate from furfuryl alcohol Green Chem. 19963

24. Tiwari M S and Yadav G D 2015 Kinetics of FriedelCrafts benzoylation of veratrole with benzoic anhydride using Cs 2.5 H 0.5 PW 12 O 40/K-10 solid acid catalyst Chem. Eng. J. 26664

25. Tambe P R and Yadav G D 2017 Selective carbonylation of o -phenylene diamine using carbon dioxide as feedstock for synthesis of 1, 3-dihydro-benzimidazol2-one over La-Zr mixed oxide J. Clean. Prod. 166 285

26. Tiwari M S and Yadav G D 2016 Novel aluminium exchanged dodecatungstophosphoric acid supported on K-10 clay as catalyst: benzoylation of diphenyloxide with benzoic anhydride $R S C A d v$. 6 49091 